\title{
Homozygosity of the Pro12Ala variant of the peroxisome proliferation-activated receptor- $\gamma 2$ (PPAR- $\gamma$ 2): divergent modulating effects on body mass index in obese and lean Caucasian men
}

\author{
J. Ek ${ }^{1}$, S. A. Urhammer ${ }^{1}$, T. I. A. Sørensen ${ }^{2}$, T. Andersen ${ }^{2,3}$, J. Auwerx ${ }^{4}$, O. Pedersen ${ }^{1}$ \\ ${ }^{1}$ Steno Diabetes Center and Hagedorn Research Institute, Copenhagen, Denmark \\ ${ }^{2}$ Danish Epidemiology Science Centre at the Institute of Preventive Medicine, Copenhagen, Denmark \\ ${ }^{3}$ Roskilde County Hospital, Denmark \\ ${ }^{4}$ U.325 INSERM, Department of Athesclerosis, Pasteur Institute, Lille, France
}

\section{Abstract}

Aims/hypothesis. The objectives of the present investigation were to examine: 1) whether a Pro115Gln variant in the peroxisome proliferator-activated receptor- $\gamma 2(P P A R-\gamma 2)$ is associated with juvenile-onset obesity among Danish Caucasianmen and 2) whether the relation of a Pro12Ala polymorphism in $P P A R-\gamma 2$ with BMI and long-term weight regulation differ between lean and obese subjects within the same cohort.

Methods. The Pro115Gln and Pro112Ala variants were examined using PCR and RFLP in a group of 752 subjects with a Body Mass Index (BMI) of 31.0 $\mathrm{kg} / \mathrm{m}^{2}$ or more and in 869 non-obese control subjects. Results. We did not find Pro115Gln in any of the 1621 male subjects we examined. Among the males with juvenile-onset obesity, the allelic frequency of the Pro12Ala polymorphism was $14 \%$ (95\% confidence interval: 12-16\%) compared with $16 \%$ (14-17\%) among the non-obese control subjects (NS). Heterozygosity of the codon 12 variant was not associated with differences in BMI or changes in body weight regulation during follow up in lean or obese subjects. In the group of obese subjects, 21 homozygous Ala12Ala carriers had, however, a higher BMI $\left(38.9 \pm 5.4 \mathrm{~kg} / \mathrm{m}^{2}\right.$ (means $\left.\pm \mathrm{SD}\right)$ vs $35.5 \pm 5.5 \mathrm{~kg} /$ $\left.\mathrm{m}^{2}, p=0.008\right)$ and a higher weight gain $(0.27 \pm 0.24$ $\mathrm{kg} \cdot \mathrm{m}^{-2} \cdot$ year $^{-1}$ vs $0.10 \pm 0.24 \mathrm{~kg} \cdot \mathrm{m}^{-2} \cdot$ year $^{-1}, p=$ $0.004)$, compared with wild-type carriers. Moreover, within the control group of 869 men the 14 homozygous carriers of the variant had a lower BMI $\left(24.4 \pm 2.7 \mathrm{~kg} / \mathrm{m}^{2}\right.$ vs $\left.26.2 \pm 3.7 \mathrm{~kg} / \mathrm{m}^{2}, p=0.005\right)$ and a slower increase in BMI $\left(0.11 \pm 0.11 \mathrm{~kg} \cdot \mathrm{m}^{-2} \cdot\right.$ year $^{-1}$ vs $0.17 \pm 0.11 \mathrm{~kg} \cdot \mathrm{m}^{-2} \cdot$ year $\left.^{-1}, p=0.002\right)$ compared with wild-type carriers.

Conclusion/interpretation. The codon 12 variant of $P P A R-\gamma 2$ is not intrinsically associated with juvenile obesity. The variant may in its homozygous form interact, however, with various combinations of genetic and environmental factors in lean and obese subjects to cause divergent modulating effects on BMI and long-term body weight control. [Diabetologia (1999) 42: 892-895]

Keywords PPAR- $\gamma 2$, mutations, obesity, body mass index changes, epidemiology.
Received: 22 December 1998 and in revised form: 3 March 1999

Corresponding author: O.Pedersen, M.D. Steno Diabetes Center, Niels Steensens Vej 2, DK-2820 Gentofte, Copenhagen, Denmark

Abbreviations: PPAR- $\gamma$, Peroxisome proliferation-activated receptor- $\gamma$; PPRE, peroxisome proliferator response element.
Peroxisome proliferation-activated receptor- $\gamma$ $(\mathrm{PPAR}-\gamma)$ is a transcription factor abundantly expressed in adipose tissue and to a lesser extent in liver, kidney and small intestines [1]. It has been shown to be involved in adipogenesis and in the regulation of adipocyte gene expression [2]. In humans, the $P P A R-\gamma$ gene consists of nine exons. Alternate use of promotors and differential splicing of the human 
form of $P P A R-\gamma$ result in two different isoforms: PPAR $-\gamma 1$ and PPAR $-\gamma 2$. The predicted human PPAR $-\gamma 2$ protein contains an additional 28 amino acids at the N-terminus compared with human PPAR$\gamma 1[1]$.

Recently, natural ligands (fatty acids and prostanoids) and agents that enhance sensitivity to insulin in vivo (thiazolidinediones) were shown to activate PPAR- $\gamma$ [3]. In addition, PPAR- $\gamma$ has a ligand-independent activation domain within the N-terminal domain, common in the two isoforms, where activity is potentiated by insulin [4]. Activation of PPAR- $\gamma$ changes the rates of transcription of genes, especially genes with a peroxisome proliferator response element (PPRE) within their promotors (e.g. uncoupling protein, phosphoenolpyruvate carboxykinase) and it has been shown that the effect of PPAR- $\gamma 2$ in this respect is more potent than the effect of PPAR$\gamma 1$. This finding is possibly explained by functional differences in their N-terminal domain [4].

Furthermore, the expression of PPAR- $\gamma 2$ mRNA in adipose tissue is increased in human obesity and a strong positive correlation exists between the ratio of PPAR $-\gamma 2 / \gamma 1$ and the body mass index (BMI) [5]. This suggests that PPAR- $\gamma 2$ may have a pivotal role in the adipocyte differentiation and in the control of BMI.

In a German study a Pro115Gln mutation in $P P A R-\gamma 2$ was suggested to be a rare cause of morbid obesity [6]. Four morbidly obese subjects out of 121 patients had this missense-mutation compared with none of 237 subjects with normal body weight. Furthermore, overexpression of the mutant gene in murine fibroblasts led to increased protein expression and an accelerated differentiation into adipocytes and an accumulation of triglyceride, compared with wild-type $P P A R-\gamma 2$ [6]. This mutation has so far not been detected in other populations. Also a Pro12Ala polymorphism of $P P A R-\gamma 2$ has been reported [7]. The Ala allele was shown to be associated with lower BMI $(p=0.027)$ and improved insulin sensitivity among 333 lean to moderately obese Finnish subjects [8]. In contrast, the Pro12Ala variant was related to higher BMI among 169 morbidly obese middle-aged American Caucasians, suggesting different mechanisms of action of the variant in these two population samples [9].

The objectives of the present investigation were to examine: 1) whether the Pro115Gln variant is associated with juvenile-onset obesity among Danish Caucasians and 2) whether the relation of the Pro12Ala polymorphism with BMI and long-term weight regulation differ between lean and obese subjects within the same cohort.

\section{Subjects and methods}

Subjects. The cohort of obese men comprised 752 subjects who had a body mass index (BMI) of $31.0 \mathrm{~kg} / \mathrm{m}^{2}$ or more at their draft board examination during 1943-1977. As a control cohort 869 draftees were selected at random (every two hundredth) from the same group. Weight and height were measured at the time of the draft examination and in 1992-1994 after an average follow-up period of 24 years. At follow-up their mean BMI was $25 \mathrm{~kg} / \mathrm{m}^{2}$. All reported themselves to be Caucasians of Danish ancestry [10]. Genomic DNA was obtained from blood samples drawn at the last examination.

Prior to participation informed consent was obtained from all subjects. The study was approved by the ethics committee of Copenhagen and was in accordance with the principles of the Helsinki Declaration II.

Preparation of genomic DNA from whole blood. Genomic DNA was isolated from human leucocyte nuclei isolated from whole blood by proteinase $\mathrm{K}$ digestion followed by phenolchloroform extraction on an Applied Biosystems 341 Nuclei Acid Purification System (Foster City, Calif., USA) or proteins were precipitated by addition of a saturated $\mathrm{NaCl}$ solution. Subsequently, genomic DNA was precipitated in ethanol.

Screening for the Pro12Ala polymorphism and the Pro115Gln mutation in PPAR- $\gamma 2$. We carried out PCR amplification of the segment with the Pro12Ala mutation in a volume of $25 \mu \mathrm{l}$, containing $100 \mathrm{ng}$ of genomic DNA, $0.2 \mu \mathrm{mol} / \mathrm{l}$ of each primer, $10 \times$ PCR Buffer II (Perkin-Elmer/Cetus, Norwalk, Conn., USA), $0.0625 \mathrm{U}$ of Taq DNA polymerase (Perkin-Elmer/Cetus) and $3.0 \mathrm{mmol} / \mathrm{l}$ of $\mathrm{MgCl}_{2}$. The PCR conditions were: denaturation at $94^{\circ} \mathrm{C}$ for 3 min followed by 40 cycles of denaturation for $30 \mathrm{~s}$, annealing at $53^{\circ} \mathrm{C}$ for $30 \mathrm{~s}$, extension at $72^{\circ} \mathrm{C}$ and a final extension at $72^{\circ} \mathrm{C}$ for $9 \mathrm{~min}$. Primers were designed from the genomic PPAR- $\gamma 2$ sequence (Genebank accession numbers: AB005520) as followed: forward primer $5^{\prime}$-CAAGCCCAGTCCTTTCTGTG-3' and the reverse primer 5'AGTGAAGGAATCGCTTTCCG-3'. Restriction fragment length polymorphism (RFLP) was detected after digestion overnight with $2 \mathrm{U}$ of HpaII (New England Biolabs, Beverly, Mass., USA) which cuts the mutant allele at a site introduced by the reverse primer (mismatched base indicated by bold letter).

We carried out PCR amplification of the segment with the Pro115Gln mutation as described above (except for $1.5 \mathrm{mmol} /$ $1 \mathrm{MgCl}_{2}, 55^{\circ} \mathrm{C}$ annealing, 35 cycles) using forward primer: $5^{\prime}-$ TGCAATCAAAGTGGAGCCTGCATGTC- $3^{\prime}$ and reverse primer: 5'-CAGAAGCTTTATCTCCACAGAC-3'. The RFLPs were detected after digestion overnight with $2 \mathrm{U}$ of HincII (New England Biolabs) which cuts the mutant allele. Primer sequence together with a mutant plasmid for positive control were kindly provided by Dr. M. Ristow and Dr. C.R.Kahn, Joslin Diabetes Center, Boston, USA. All fragments were resolved on a $3 \%$ agarose gel and made visible by staining with ethidium bromide.

Statistics. When appropriate Chi-squared analysis and Fisher's exact test were applied to test for significant differences in allele frequencies. Differences in continuous variables between groups of subjects were tested with Student's $t$ test when the distribution of the variable or of the logarithmically transformed variable approached a normal distribution and the variances of the variables were equal in the groups compared. Otherwise the Mann-Whitney rank sum test was used. Data are means and standard deviation (SD). A $p$-value less than 
Table 1. Clinical characteristics of 752 obese and 869 lean Caucasian men classified in accordance with their genotype of the Pro12Ala polymorphism of the PRAR- $\gamma 2$ gene

\begin{tabular}{|c|c|c|c|c|c|}
\hline & Pro12Pro & Pro12Ala & $\mathrm{p}$ & Ala12Ala & $\mathrm{p}$ \\
\hline \multicolumn{6}{|l|}{ Obese } \\
\hline$n$ & 540 & 191 & & 21 & \\
\hline Age at follow-up (year) & $43.1(6.2)$ & $43.1(6.2)$ & 0.77 & $42.1(3.6)$ & 0.43 \\
\hline BMI at follow-up $\left(\mathrm{kg} / \mathrm{m}^{2}\right)$ & $35.5(5.5)$ & $36.0(5.9)$ & 0.50 & $38.9(5.4)$ & 0.008 \\
\hline$\Delta \mathrm{BMI} /$ year $\left(\mathrm{kg} \cdot \mathrm{m}^{-2} \cdot\right.$ year $\left.^{-1}\right)$ & $0.10(0.24)$ & $0.12(0.27)$ & 0.16 & $0.27(0.24)$ & 0.004 \\
\hline \multicolumn{6}{|l|}{ Non-obese } \\
\hline BMI at draft board $\left(\mathrm{kg} / \mathrm{m}^{2}\right)$ & $21.7(2.4)$ & $21.5(2.1)$ & 0.56 & $21.7(2.1)$ & 0.44 \\
\hline BMI at follow-up $\left(\mathrm{kg} / \mathrm{m}^{2}\right)$ & $26.2(3.7)$ & $26.0(3.2)$ & 0.25 & $24.4(2.7)$ & 0.005 \\
\hline$\Delta \mathrm{BMI} /$ year $\left(\mathrm{kg} \cdot \mathrm{m}^{-2} \cdot\right.$ year $\left.^{-1}\right)$ & $0.17(0.1)$ & $0.16(0.1)$ & 0.45 & $0.11(0.1)$ & 0.002 \\
\hline
\end{tabular}

Values are mean (SD). The $p$ value compares subjects heterozygous (Pro12Ala) or homozygous (Ala12Ala) for the polymorphism with subjects carrying the wild-type (Pro12Pro)

0.05 (two-tailed) was considered significant. Statistical Package of Social Science (SPSS) for Windows, version 7.5, was used for statistical analysis.

\section{Results}

The Pro115Gln mutation was not found in any of the 1621 subjects examined.

The allelic frequency of the Pro12Ala polymorphism in the PPAR- $\gamma 2$ gene was $14 \%$ (95\% CI: $12-16 \%$ ) among 752 males with juvenile-onset obesity and $16 \%(14-17 \%)$ among 869 control subjects (NS). The observed genotypes were in the HardyWeinberg equilibrium. Neither in the lean nor in the obese group of subjects, did the heterozygous carriers of the codon 12 polymorphism differ with respect to BMI at the draft board examination or to BMI at the end of the follow-up period compared with findings in wild-type carriers. Yet, within the cohort of obese men, 21 homozygous carriers $(2.8 \%$ of the population) of the codon 12 variant were identified. These subjects had higher BMI at the time of re-examination (mean age 43 years) than wild-type carriers $\left(38.9 \pm 5.4 \mathrm{~kg} / \mathrm{m}^{2}\right.$ vs $\left.35.5 \pm 5.5 \mathrm{~kg} / \mathrm{m}^{2}, p=0.008\right)(\mathrm{Ta}-$ ble 1). Also $\triangle \mathrm{BMI} /$ year was higher among Ala12Ala carriers than wild-type carriers $(0.27 \pm 0.24 \mathrm{~kg}$. $\mathrm{m}^{-2} \cdot$ year $^{-1}$ vs $0.10 \pm 0.24 \mathrm{~kg} \cdot \mathrm{m}^{-2} \cdot$ year $\left.^{-1}, p=0.004\right)$. Within the control group, 14 homozygous carriers (1.6\% of the group) of the variant had lower BMI $\left(24.4 \pm 2.7 \mathrm{~kg} / \mathrm{m}^{2}\right.$ vs $\left.26.2 \pm 3.7 \mathrm{~kg} / \mathrm{m}^{2}, p=0.005\right)$ and lower $\Delta \mathrm{BMI} /$ year $\left(0.11 \pm 0.11 \mathrm{~kg} \cdot \mathrm{m}^{-2} \cdot\right.$ year $^{-1}$ vs $0.17 \pm 0.11 \mathrm{~kg} \cdot \mathrm{m}^{-2} \cdot$ year $\left.^{-1}, \quad p=0.002\right)$, compared with wild-type carriers (Table 1). There was no difference between the number of homozygous carriers in lean and obese subjects $(p=0.072)$.

\section{Discussion}

In contrast to a recent report [6], we were not able to detect the Pro115Gln mutation in PPAR- $\gamma 2$ in any of the 1621 subjects we examined, suggesting that this variant is highly unlikely to be involved in the pathogenesis of juvenile-onset obesity in Danish Caucasians. Thus, our finding supports the notion that the rare incidences of obese Pro115Gln carriers in the German study may reflect a founder effect. It should be emphasised that the probability of missing the detection of a Pro115Gln mutation is negligible, since a positive control sample was included in our screening assay.

Regarding the Pro12Ala polymorphism of the gene we found an allelic frequency similar to previous studies [7-9]. The variant was not intrinsically associated with obesity. Among 869 subjects with normal body weight at the draft board examination, the polymorphism in its homozygous form was, however, related to a lower BMI $(p=0.005)$ and a relatively lower increase in BMI at follow-up (average age: 48 years $)(p=0.002)$ which is in line with a previous study in Finnish non-obese subjects, where 5 subjects homozygous and 71 subjects heterozygous for the variant (mean age of 44 years) had lower BMI than 257 wild-type carriers (mean age of 45 years) $(p=0.0027)$. In the Finnish study the variant was also shown to be associated with an improved insulin sensitivity [8].

Interestingly, the present study also showed a higher BMI $(p=0.008)$ and a higher increase in BMI during follow-up $(p=0.004)$ in obese subjects homozygous for the Pro12Ala variant than wild-type carriers. This finding contrasts with our finding among the lean subjects but accords with the recent report from studies of American Caucasians with morbid obesity where a group of 28 subjects, homozygous and heterozygous for the variant, had higher BMI compared with 141 wild-type carriers (mean age of 41-43 years) 
$(p<0.001)$ [9]. There is no obvious explanation for the discrepancy between lean and obese subjects but the results could indicate a variable interaction of the Ala allele with other genetic and environmental factors with regulatory effects on BMI and longterm changes in body weight. Apparently, these unknown genetic and non-genetic factors differ greatly between obese and lean subjects. Thus, lean subjects carrying the codon 12 polymorphism may, as suggested by the Finnish study [8], have an increased insulin sensitivity which is maintained due to specific combinations of lifestyle and genetic factors, whereas theoretically an increased insulin sensitivity of adipose tissue could contribute to fat accumulation and obesity in subjects predisposed for obesity. Given the intrinsic lack of association of the Pro12Ala polymorphism with obesity, it seems, however, equally likely that this genetic variant is not directly involved in the pathogenesis of obesity.

In conclusion, the Pro12Ala variant of PPAR- $\gamma 2$ does not itself influence the development of juvenile-onset obesity among Danish Caucasians. Yet, the homozygous codon 12 variant may in the context of pre-existing obesity lead to a further increase in obesity whereas in groups not prone to weight gain the opposite effect is observed pointing to the importance of the genetic background for the impact of this amino acid polymorphism.

Acknowledgements. The study was supported by grants from the University of Copenhagen, the Velux Foundation, the Danish Diabetes Association, the Danish Medical Research Council, the Danish Heart Foundation and EEC (BMH4-CT950662). The authors thank S. Urioste, D. Gøth-Johansen, A. Forman, L. Aabo and B. Mottlau for dedicated and careful technical assistance and G. Lademann for secretarial support.

\section{References}

1. Fajas L, Auboeuf D, Raspé E et al. (1998) The organization, promotor analysis, and expression of the human PPAR $\gamma$ gene. J Biol Chem 272: 18779-18789

2. Wu Z, Xie Y, Bucher NL, Farmer SR (1995) Conditional ectopic expression of C/EBP beta in NIH-3T3 cells induces PPAR gamma and stimulates adipogenesis. Genes Dev 9: 2350-2363

3. Elbrecht A, Chen Y, Cullinan CA et al. (1996) Molecular cloning, expression and characterization of human peroxisome proliferator activated receptors gamma 1 and gamma 2. Biochem Biophys Res Commun 224: 431-437

4. Werman A, Wollenberg A, Solanes G, Bjørkbæk C, VidalPuig AJ, Flier JS (1997) Ligand independent activation domain in the N-terminus of peroxisome proliferator- $\gamma$ (PPAR- $\gamma$ ) J Biol Chem 272: 20230-20235

5. Vidal-Puig AJ, Considine RV, Jimenez-Linan $M$ et al. (1997) Peroxisome proliferator-activated receptor gene expression in human tissues. J Clin Invest 99: 2416-2422

6. Ristow M, Muller-Wieland D, Pfeiffer A, Krone W, Kahn CR (1998) Human obesity associated with a mutation in $\operatorname{PPAR} \gamma 2$, a regulator of adipocyte differentiation. $\mathrm{N}$ Eng $\mathrm{J}$ Med 339: 953-959

7. Yen CJ, Beamer BA, Negri C et al. (1997) Molecular scanning of the human peroxisome proliferator-activated receptor- $\gamma$ (PPAR- $\gamma$ ) gene in diabetic Caucasians: identification of a Pro12Ala PPAR $\gamma 2$ missense mutation. Biochem Biophys Res Commun 240: 270-274

8. Deeb SS, Fajas L, Nemoto M et al. (1998) Pro12Ala substitution in PPAR $\gamma 2$ associated with decreased receptor activity, lower body mass index and improved insulin sensitivity. Nat Genet 20: 284-287

9. Beamer BA, Yen CJ, Andersen RE et al. (1998) Association of the Pro12Ala variant in the peroxisome proliferator-activated receptor- $\gamma 2$ gene with obesity in two Caucasian populations. Diabetes 47: 1806-1808

10. Sonne-Holm S, Sørensen TIA, Jensen G, Schnohr P (1989) Longterm changes in body weight in adult obese and nonobese men. Int J Obes 14: 319-326 